\title{
X-ray computed tomography in life sciences
}

\author{
Shelley D. Rawson, Jekaterina Maksimcuka, Philip J. Withers and Sarah H. Cartmell*
}

\begin{abstract}
Recent developments within micro-computed tomography $(\mu \mathrm{CT})$ imaging have combined to extend our capacity to image tissue in three (3D) and four (4D) dimensions at micron and sub-micron spatial resolutions, opening the way for virtual histology, live cell imaging, subcellular imaging and correlative microscopy. Pivotal to this has been the development of methods to extend the contrast achievable for soft tissue. Herein, we review the new capabilities within the field of life sciences imaging, and consider how future developments in this field could further benefit the life sciences community.

Keywords: X-ray computed tomography, Correlative microscopy, Phase contrast, Lightsheet, Time-lapse tomography, 3D imaging, 3D histology, Elemental mapping, Quantitative tomography, Water window
\end{abstract}

\section{Non-invasive 3D microscopy over multiple scales}

A range of $2 \mathrm{D}$ imaging tools, from optical microscopy to transmission electron microscopy, underpin much of what we know about structure-functionality relationships in biology, aided by a marked increase in the labels and markers available to identify certain features. To some extent, light and electron microscopy workflows have been developed to enable 3D imaging. However, they are limited by optical transparency (required for confocal and lightsheet), technically demanding sample preparation (e.g. freezing or fixing and embedding in resin followed by serial sectioning) and a limited field of view (as in transmission electron microscopy). Computed tomography (CT) exploiting the penetrating power of Xrays, on the other hand, allows non-invasive imaging of a large field of view, even for optically opaque materials, across a range of resolutions (Fig. 1), and sample preparation is comparatively straightforward. Micro-computed tomography ( $\mu \mathrm{CT} ; \sim 1 \mu \mathrm{m}$ to $>100 \mu \mathrm{m}$ spatial resolution) was first introduced for research applications in 1982 when Elliott et al. [6] imaged the interior of a Biomphalaria glabrata snail shell (Fig. 2a). Subsequent advances in $\mu \mathrm{CT}$ are evident from the corresponding image in Fig. $2 \mathrm{~b}$ showing early stage biomineralisation of aragonite taken more recently by synchrotron $\mu \mathrm{CT}$. These advances,

\footnotetext{
* Correspondence: sarah.cartmell@manchester.ac.uk

The Henry Royce Institute and School of Materials, The University of Manchester, Manchester M13 9PL, UK
}

alongside nano-computed tomography (nCT; down to $\sim 10 \mathrm{~nm}$ voxel size), now allow 3D imaging from the organism level all the way down to the level of the organelles within the cell.

In essence, $\mathrm{CT}$ imaging involves taking many (typically over 1000) X-ray projections (digital radiographs) from different angles around a sample (typically through $360^{\circ}$ or $\left.180^{\circ}\right)$. The X-ray projections reveal the attenuation of $\mathrm{X}$-rays as they pass through the sample. The data are then computationally reconstructed, producing a greyscale virtual 3D volume of the attenuation capability of the sample. Once the 3D data set has been reconstructed, virtual slices (similar to virtual histology sections) can be extracted at any orientation and depth for viewing. Alternatively, segmentation (often on the basis of greyscale thresholding) can be used to distinguish certain constituents in 3D, allowing volumetric quantification, such as the connectivity of vascular networks [8], porosity (interconnectivity, density and pore distribution) within a biomaterial [9] or the diameter and distribution of cells within a tissue [10]. Quantification can also be undertaken by densitometric measurements, for example by comparing the attenuation of bone against a calibrant phantom to allow bone mineral density to be quantified in osteoporosis [11].

Regarding the optimal magnification and resolution for imaging a given subject, it should be noted that the spatial resolution is not equal to the voxel (3D pixel) size, but is often $\sim 2-3$ times larger [12]. Further, while 


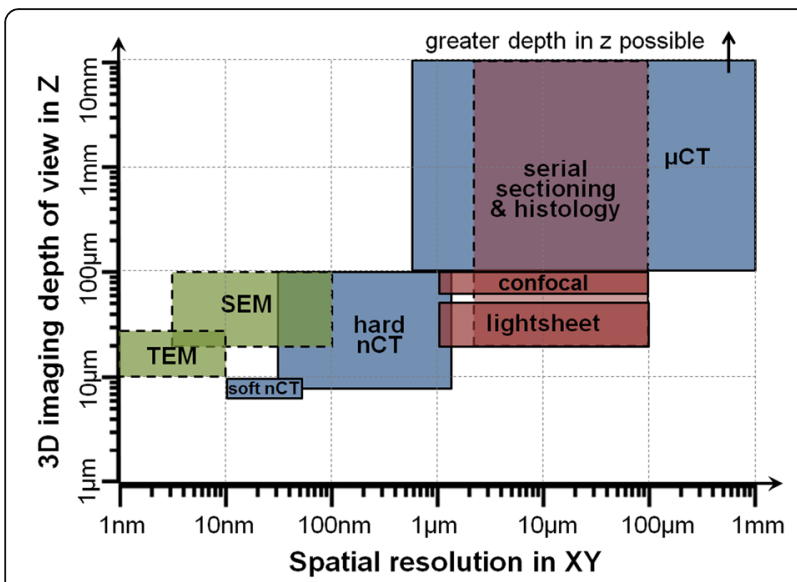

Fig. $13 \mathrm{D}$ imaging techniques for life sciences applications, shown according to their spatial resolution (in XY) and the full depth (in Z) of the volume that can be imaged (accumulated over many serial sections for destructive methods). Blue $=\mathrm{CT}$ techniques, green $=$ electron microscopy techniques, pink = light microscopy techniques. Solid line $=$ non-invasive, dashed line $=$ destructive. TEM serial section transmission electron microscopy, SEM serial section scanning electron microscopy, Soft nCT soft nano-computed tomography, Hard nCT hard nano-computed tomography, $\mu C T$ micro-computed tomography. Data from [1-5]

region of interest (ROI) imaging [13] means that the sample need not be wholly within the field of view, in the majority of cases this condition is applied. This limits the effective pixel size to the sample width divided by the number of pixels across the detector, thereby limiting the resolution. Generally the attenuation of X-rays increases sharply with the atomic number of the constituents or sample size, and decreases sharply with increasing X-ray energy. Consequently, larger volume $(\mu \mathrm{CT})$ systems tend to operate at high energy around 90-225 $\mathrm{keV}$, while $\mathrm{nCT}$ systems generally operate below $10 \mathrm{keV}$. Soft tissue contrast improves as the X-ray energy is decreased, and so selecting the optimal energy is critical to obtaining good signal to noise ratio. CT configurations include cone beam (typical of lab $\mu \mathrm{CT}$ systems), parallel beam (typical of synchrotron X-ray systems) and helical scanning (typical of medical imaging) [14]; and magnification can be achieved either with or without lenses [15].

It should be borne in mind when imaging at high resolutions at synchrotron sources that the flux (photons $/ \mathrm{m}^{2}$ s) can be sufficient to cause localised heating. Further, given that a certain number of photons must be detected from the imaged volume in order to reconstruct an acceptable signal to noise 3D image, the X-ray exposure (photons $/ \mathrm{m}^{3}$ ) increases according to $\sim(1 /$ (width of the $\mathrm{ROI})^{3}$ ) and the time needed to acquire the image typically increases with increasing spatial resolution. The former is of particular importance when imaging live and fixed biological tissues because the increased X-ray dose associated with high resolutions can cause significant damage to soft tissues [16] and alter the mechanical properties of hard tissues such as bone [17]. Generally speaking, damage is negligible for $\mu \mathrm{CT}$, such that live cells remain viable after imaging at micron spatial resolution [18], whereas freezing is commonplace to minimise cell structural damage when imaging at the tens of nanometres scale [19]. DNA damage of museum specimens (such as sub-fossilised bones or preserved skin) is not a concern for laboratory CT at doses below $200 \mathrm{~Gy}$ [20], which is unlikely to be exceeded for micron resolution imaging. Several methods have been used to
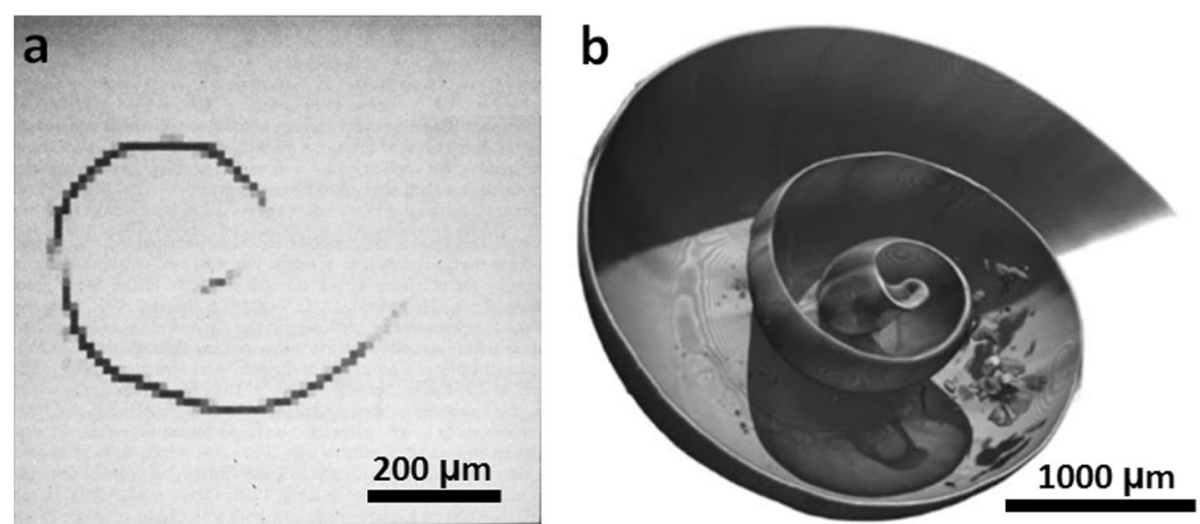

Fig. $2 \mu \mathrm{CT}$ imaging of Biomphalaria glabrata snail shell. a First use of $\mu \mathrm{CT}$ imaging, at a voxel (3D pixel) size of $12 \mu \mathrm{m}$, reproduced with permission from [6]. b Synchrotron $\mu \mathrm{CT}$ imaging showing the latero-frontal view of a 4-week-old snail at a voxel size of $6.2 \mu \mathrm{m}$ with a virtual section in the median plane. Image in b reproduced from [7], Marxen JC, Prymark O, Beckmann F, Neues F, Epple M. Embryonic shell formation in the snail Biomphalaria glabrata: A comparison between scanning electron microscopy (SEM) and synchrotron radiation micro computer tomography (SRHCT). Journal of Molluscan Studies. 200,874(1);19-26, by permission of Oxford University Press 
minimise structural damage when imaging at high resolutions, including increasing detector efficiency, resin embedding [21], fixing and drying [22] and cryopreservation of the samples via vitrification or high pressure freezing, which minimises cryo-damage [21, 23]. Freezing can also be followed by freeze substitution and Epon embedding (often used in electron microscopy), thereby minimising X-ray damage and preventing sample movement, but without the need to keep the sample frozen during imaging [23].

Provided X-ray damage can be avoided, the noninvasive nature of X-ray imaging presents the opportunity to track cells over time in vivo [24], observe changes in a sample over time in response to external stimuli $[25,26]$ or to use CT correlatively to complement other techniques. This paper reflects on recent technological advances and their application to the field of life sciences, and provides perspective on future opportunities.

\section{Obtaining contrast for soft tissue imaging in aqueous conditions}

Achieving good contrast is critically important to resolve and segment features within a sample. Life science samples present two key challenges for CT imaging. Firstly, there is typically little to no X-ray attenuation contrast between soft tissues (Fig. 3a, b). Secondly, very highly attenuating hard materials (e.g. calcified tissues or implants) positioned close to low attenuating soft tissues can result in streak artefacts which can obscure the view of the soft tissue [29].

Several techniques have emerged to obtain sufficient contrast between soft tissues, including phase contrast tomography (PCT), sample staining using heavy metals, nanoparticle labelling of cells, soft X-ray 'water window' imaging and dual energy CT.

In general, phase contrast (Fig. 3a) primarily enhances the visibility of the interfaces between soft tissues, such as muscle, tendon, adipose tissue and skin, along with Goods buffers and polymeric biomaterials. There are several means of achieving phase contrast [30]; however, in essence these all take advantage of the phase change generated by the refractive index as X-rays pass through the sample. For the most part, synchrotron Xray beamlines are highly coherent, giving high contrast interference fringes, which makes PCT relatively straightforward, whereas few laboratory systems currently exhibit sufficient coherence to undertake phase contrast imaging without the use of gratings or masks [31]. PCT is being increasingly applied to the 3D imaging of soft tissues across a wide variety of applications including non-calcified musculoskeletal tissues (such as cartilage and tendon) [32,33], the circulatory system [34] and plants [35]. PCT has proven particularly useful for fossilised specimens, where alternative means of contrast enhancement (such as staining) are not suitable [36].

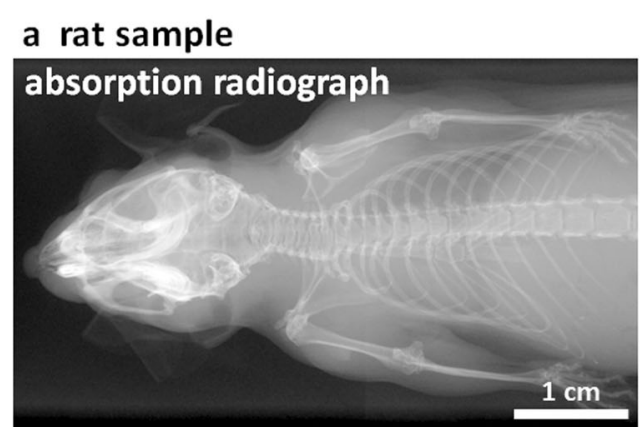

b alligator head
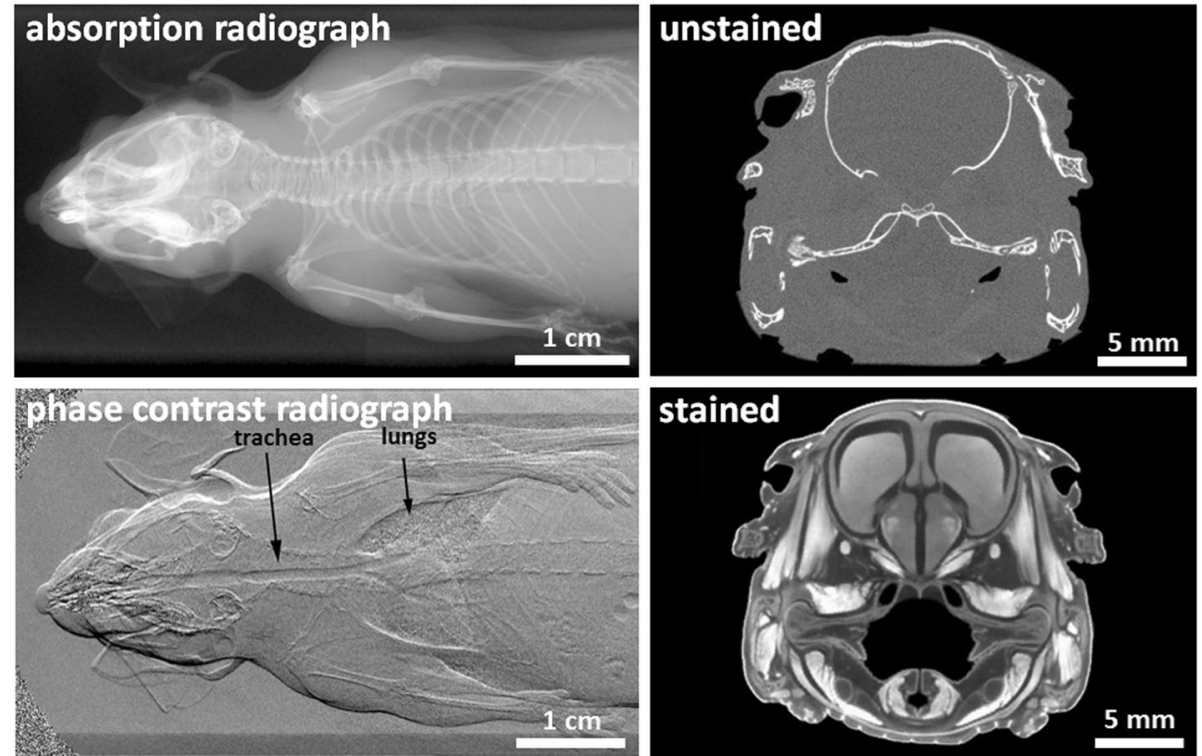

Fig. 3 Optimising X-ray contrast. a A comparison of conventional attenuation (absorption) contrast and phase contrast radiographs of a rat, reproduced with permission from [27]. b CT section of an alligator head before and after 2 weeks of iodine staining, reproduced with permission from [28]. In a the conventional radiograph reveals the bone structure but not the soft tissue, whereas under grating-based phase contrast the soft tissues, including trachea and lungs, are well defined, the bones less so; in $\mathbf{b}$ only the bones are clear in the unstained sample, whereas staining reveals the soft tissues 
Heavy metal staining can be used to improve the attenuation contrast for soft tissue CT absorption imaging. Sample staining with a heavy metal contrast agent exploits the preferential up-take of the stain by different tissues, which then attenuate more significantly in the resultant CT images [37] (Fig. 3b). While staining is well established in electron microscopy, fluorescent microscopy and histology, staining for CT imaging is in its relative infancy. To date only a few stains have been described in the literature, based mainly around those used for electron microscopy (which is also sensitive to heavy elements), including those containing iodine, tungsten, molybdenum and osmium (Table 1) [43, 45, 46]. The use of iodine has become commonplace, providing excellent contrast alongside ease of handling and cost effectiveness, and a range of staining protocols have been detailed [38]. Few studies have considered the merits of different iodine staining protocols, although iodine-ethanol solution has been found to be more effective than iodine potassium iodide at achieving greater contrast [47]. Staining duration is sample- and stain-specific; full staining is achieved in murine heart and lungs in just $3 \mathrm{~h}$ using an iodine or gadolinium stain [48], whereas larger specimens, such as alligator and emu heads, can require weeks of staining [28]. Mathematical models are being developed to predict the staining uptake within tissues, based on mass transfer theory [49]. However, at present a time-course study is recommended to determine the ideal staining duration of a particular tissue type with a given stain [50].

Several studies have compared the relative benefits of the CT stains used to date across a range of zoological and plant specimens $[43,46]$. Nevertheless, there remains great scope for further CT stain development, in terms of both the library of available stains and the characterisation of staining uptake by different tissue types.
In cases where the vasculature is of interest, staining can also be achieved by the perfusion of a contrast agent through the blood vessels. This has been used to stain whole-body murine samples in just $30 \mathrm{~min}$ [44]. Alternatively a resin can be perfused into the blood vessels to produce a vascular cast. Upon resin polymerisation the tissue can be removed leaving only the vascular cast [51]. Whilst staining provides good tissue contrast, stains are cytotoxic and typically require prior chemical fixation to minimise tissue shrinkage [52] (Table 2). Preliminary studies should consider the shrinkage or swelling effects on the tissue or specimen of interest during selection of fixation and staining protocols. Samples may also be dried, frozen or embedded as part of sample preparation, as an alternative means of enhancing contrast or to provide stability to the samples during scanning, respectively (Table 2 ).

Gold nanoparticle ( $\sim 5$ to $200 \mathrm{~nm}$ in diameter) labelling is an emerging technique for the labelling of live cells (Fig. 4a). It allows tracking of therapeutic cells after they have been introduced in vivo to see if they migrate to, and continue to remain at, the target site within the body [59]. The high atomic number of gold (atomic number $=79$ ) means that nanoparticles attenuate $\mathrm{X}$-rays to a much greater degree than soft tissues, providing good imaging contrast. Regarding concerns over toxicity [63, 64], many studies report that gold nanoparticles are not detrimental to the functionality of the therapeutic cell, as observed in mesenchymal stem cells, human T cells, A-431 human squamous carcinoma cells and monocytes, among others [65-67]. The ecotoxicology of nanoparticles has also been considered by observing their uptake and expulsion over time in B. glabrata freshwater snails [68].

For the imaging of intracellular detail, soft X-ray 'water window' tomography (soft $\mathrm{nCT}$ ) is able to provide

Table 1 Summary of heavy metal stains used to enhance soft tissue contrast in CT. Asterisks indicate the most commonly used stains

\begin{tabular}{|c|c|c|c|}
\hline Heavy metal & Staining solution & Binds to & Staining considerations \\
\hline lodine $*[38]$ & $\begin{array}{l}\text { lodine potassium iodide in } \\
\text { water, ethanol or methanol. } \\
\text { Various concentrations }\end{array}$ & $\begin{array}{l}\text { Non-specific staining. Preferentially } \\
\text { binds to lipids and glycogen. } \\
\text { Good for muscle fibres, nerve myelin } \\
\text { sheath, connective tissues and the } \\
\text { eye lens }\end{array}$ & $\begin{array}{l}\text { - Rapid and deep tissue penetration } \\
\text { - Particularly suited to larger specimen (> } 2 \mathrm{~mm}) \\
\text { - An effective stain for flower parts, allowing } \\
\text { counting of pollen ovules [39] } \\
\text { - Has been used to study water transport in plants [35] }\end{array}$ \\
\hline $\begin{array}{l}\text { Tungsten and } \\
\text { Molybdenum* [40] }\end{array}$ & $\begin{array}{l}\text { Phosphotungstic acid } \\
\text { Phosphomolibdic acid }\end{array}$ & $\begin{array}{l}\text { Proteins including fibrin and collagen. } \\
\text { Suited to connective tissues }\end{array}$ & $\begin{array}{l}\text { - Moderate tissue penetration rate and depth } \\
\text { - Can provide more detailed visualisation compared } \\
\text { with iodine-based stains } \\
\text { - Phosphotungstic acid also effective in plants [41] }\end{array}$ \\
\hline Osmium* [42] & $\begin{array}{l}\text { Osmium tetroxide, as used } \\
\text { in electron microscopy }\end{array}$ & $\begin{array}{l}\text { Lipids including those in cell membranes, } \\
\text { some proteins and nucleic acids }\end{array}$ & $\begin{array}{l}\text { - Tissue penetration is slow and can be limited } \\
\text { (not suited to samples requiring a penetration } \\
\text { depth greater than } 1-2 \mathrm{~mm} \text { ) } \\
\text { - Highly toxic, requiring special safety considerations }\end{array}$ \\
\hline Indium [43] & Gallocyanin-chromalum & $\begin{array}{l}\text { Cell nuclei. Can show cell density and } \\
\text { individual cells }\end{array}$ & $\begin{array}{l}\text { - A histology stain } \\
\text { - Low contrast overall }\end{array}$ \\
\hline $\begin{array}{l}\text { lodine, aluminium } \\
\text { and iron [44] }\end{array}$ & Verhoff's Stain & Arterial walls of the vascular network & - A trichrome histology stain \\
\hline
\end{tabular}


Table 2 Summary of sample preparation techniques

\begin{tabular}{|c|c|c|}
\hline Preparation & Protocol & Considerations \\
\hline Drying & $\begin{array}{l}\text { Air drying, HDMS or critical point drying (for cells) } \\
\text { and freeze drying (for tissues) [53] }\end{array}$ & $\begin{array}{l}\text { - Samples become very delicate } \\
\text { - Subsequent fixation not possible } \\
\text { - Long or thin parts prone to movement during scanning } \\
\text { - Compatible with electron microscopy in correlative imaging }\end{array}$ \\
\hline $\begin{array}{l}\text { Chemical } \\
\text { fixation }\end{array}$ & $\begin{array}{l}10 \% \text { neutral buffered formalin }[54] \\
1 \% \text { glutaraldehyde in acetone }[55] \\
\text { Copenhagen mix (for plants: } 70 \% \text { absolute alcohol, } \\
2 \% \text { glycerol, } 28 \% \text { water) }[41]\end{array}$ & $\begin{array}{l}\text { - Typically used before heavy metal staining to minimise sample shrinkage } \\
\text { - Imaging may be performed in liquid or air (typically ethanol or distilled water) } \\
\text { - Sample may move during scanning; measures to prevent movement such as } \\
\text { packing with foam are advised } \\
\text { - If imaging in air, measures to prevent drying are advised (e.g. placing sample } \\
\text { in sealed container with a small reservoir of liquid to maintain humidity) }\end{array}$ \\
\hline Embedding & Resin [56] or wax [34] & $\begin{array}{l}\text { - Effective at preventing sample movement } \\
\text { - Good for samples with long or thin parts which may otherwise vibrate during } \\
\text { scanning, causing blurred imaging } \\
\text { - Can be used with or without staining } \\
\text { - Resin compatible with block face serial sectioning for correlative imaging }\end{array}$ \\
\hline Freezing & Freezing [57] or vitrification [19] & $\begin{array}{l}\text { - Use of a cryo-stage is necessary during } C T \text { imaging of frozen samples } \\
\text { - Vitrification is typical for soft nCT as it minimises cryo-damage }\end{array}$ \\
\hline \multirow[t]{2}{*}{ Native tissue } & No fixative, with staining [26] & $\begin{array}{l}\text { - Used to provide contrast whilst minimising change in tissue mechanical } \\
\text { properties (iodine in phosphate buffered saline has been used for this } \\
\text { purpose) }\end{array}$ \\
\hline & No fixative, no staining [58] & $\begin{array}{l}\text { - Fix and stain unsuited to some tissues due to uptake of fluid causing } \\
\text { swelling, e.g. intervertebral disc }\end{array}$ \\
\hline
\end{tabular}

unprecedented imaging of cell organelles (Fig. 4b) at a spatial resolution better than $50 \mathrm{~nm}$ [69], as close to their native state as possible. Compared to hard X-rays (>5 keV), soft X-rays (below $1 \mathrm{keV}$ ) with photon energies between $284 \mathrm{eV}$ and $543 \mathrm{eV}$ are said to be in the 'water window' region in which water is essentially transparent [4]. This is because X-ray photons in this energy range are absorbed an order of magnitude more readily by carbon and nitrogen in biological tissues than by oxygen in water. Using soft $\mathrm{nCT}$, cells are typically vitrified, both to embed the cells in a medium and to minimise X-ray damage during imaging [19]. A variety of cellular processes have been studied to date by soft nCT [19]. Within the cell, different organelles (the nucleus, endoplasmic reticulum, mitochondrial network and plasma membrane) can be clearly identified and segmented to produce a $3 \mathrm{D}$ view of the organelles (Fig. 4b), determine their size [60] and identify their interactions (Fig. 4c). Until recently, soft nCT could only be undertaken on synchrotron beamlines [19]; however, laboratory-source soft nCT systems are becoming available [70].

Dual energy CT imaging can be used both to increase the contrast of soft tissue in samples containing both hard and soft tissue, as well as for identifying different stains, rather like multiple fluorescent compounds can be distinguished in optical imaging. As illustrated in Fig. 4d for imaging feline skin [62], dual energy CT involves imaging tissue first with X-rays of one energy range and then again with $\mathrm{X}$-rays of a different energy range [71]. In this case phosphotungstic acid and iodine potassium iodide dual staining was used to identify collagenous and adipose tissues, respectively.
Another example is dual energy imaging of a mouse toe by Handschuh et al. [62], where the percentages of hydroxyapatite, $\mathrm{I}_{2} \mathrm{KI}$ stain and water (background) in each voxel of the scan were identified to observe calcified tissues and soft tissues. The data sets for each material are then overlaid to produce a composite image showing the different tissue types, and segmentation can provide a $3 \mathrm{D}$ view of the different tissues. Lab-based spectral imaging systems incorporating photon-counting energy-resolving detectors are now available. These are able to assign photons to a small number of energy thresholds per pixel and can thus distinguish multiple stains simultaneously [72]. The logical extension of this approach is hyperspectral CT using an energy-sensitive detector to record the full X-ray energy profile at each pixel [73]. This means the absorption edges of multiple stains or key elements, e.g. $\mathrm{Ca}^{2+}$, can be recorded using white Xray illumination to map the $3 \mathrm{D}$ distribution of certain elements. Hyperspectral imaging allows for finer energy resolution, whereby multiple elements can be identified without prior knowledge of sample composition, as demonstrated to date in materials science applications [73].

\section{Imaging of tissues and cells on the micro- and nano-scale}

CT provides a unique view of cells as it bridges the gap between the capabilities of light and electron microscopy imaging techniques (Fig. 1). nCT can provide views of sub-cellular detail, but can also provide a large enough field of view to observe the cell in the wider context of 



Orthoslice

Nucleus $\square /$ Nucleolus

Mitochondria

Lipid bodies

Complete
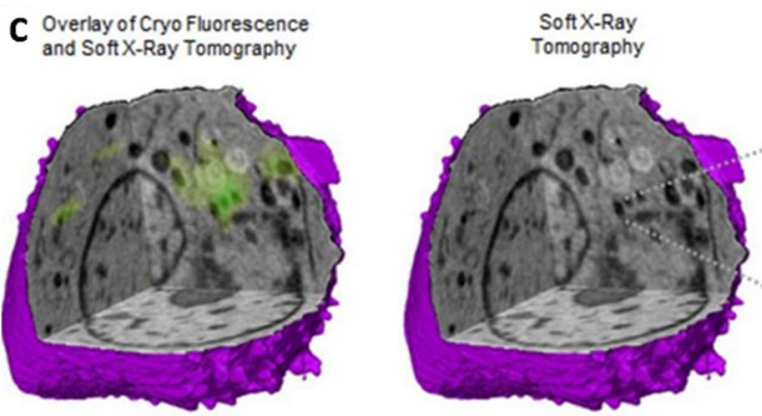

Segmentation


Fig. 4 Emerging techniques for enhancing contrast in soft tissues. a Gold nanoparticle labelling; 3D segmented image showing clusters of gold nanoparticle labelled cells within a mouse (cells are yellow, circled with red dotted line) [59]. b Water window imaging showing a soft nCT section through a diploid yeast cell, the reconstructed $C T$ volume alongside 3D representations of individual organelles and the composite image overlaying all organelles, reproduced with permission from [60]. c Correlative water window imaging with cryo-fluorescent microscopy; reconstructed soft X-ray tomograph of a mouse lymphoblastoid cell and overlaid cryo-fluorescence, soft X-ray tomograph alone and an expanded 3D segmented view of a mitochondrion and endoplasmic reticulum from within the cell [61]. $\mathbf{d}$ Dual energy CT; feline skin double stained with phosphotungstic acid, which preferentially stains collagen and other connective tissue (corium), and iodine potassium iodide, which stains adipose tissue (subcutaneous fat), imaged at (left) $40 \mathrm{kV}$ and (middle) $80 \mathrm{kV}$, the former being more sensitive to PTA, (right) decomposition of the two contributions (right) to show adipose (yellow) and collagenous (pink) tissues, reproduced with permission from [62] Image in a reprinted from [59], Nanomedicine, 10(8), Astolfo A, Qie F, Kibleur A, Hao X, Menk RH, Arfelli F, et al. A simple way to track single gold-loaded alginate microcapsules using $\mathrm{x}$-ray CT in small animal longitudinal studies, p.1821-8, 2014, with permission from Elsevier. Image in c reproduced with permission from [61], Journal of Cell Science: Elgass KD, Smith EA, LeGros MA, Larabell CA, Ryan MT. J Cell Sci, 2015;128(15):2795-804

the surrounding extracellular matrix. Indeed $\mu \mathrm{CT}$ can inform on the position, density and distribution of cells either within a tissue or on a tissue-engineered scaffold.

Nanoscale imaging can be broadly split into hard $(>5$ $\mathrm{kV})$ and soft $(<1 \mathrm{kV}) \mathrm{X}$-ray $\mathrm{nCT}$. As mentioned in the
"Obtaining contrast for soft tissue imaging in aqueous conditions" section, the latter exploits the water window to image soft tissue. The limited penetration of soft Xrays means soft $\mathrm{nCT}$ is limited to a sample thickness of $\sim 10 \mu \mathrm{m}$ [74], whereas samples many tens of microns in 
diameter can be imaged using hard $\mathrm{nCT}$ at a spatial resolution down to $50 \mathrm{~nm}$ [15]. This provides the possibility of imaging cells within native tissues or when seeded onto biomaterial scaffolds, whereas soft $\mathrm{nCT}$ has typically been used to image adherent cells cultured on 2D surfaces [75], or cells in suspension [61]. For example, hard $\mathrm{nCT}$ has been used to observe human femur over a field of view of $9 \mu \mathrm{m}$ containing 17 lacunae, at a voxel size of $60 \mathrm{~nm}$, in which collagen fibre orientation within the bone matrix could also be identified [76]. For soft tissue imaging using hard nCT, additional techniques must be used to attain sufficient contrast, which are not necessary with soft X-rays (see the "Obtaining contrast for soft tissue imaging in aqueous conditions" section). It is possible to identify fibroblast cells and their nuclei on polymeric biomaterial tissue scaffolds using Zernike phase contrast by laboratory source nCT at $150 \mathrm{~nm}$ spatial resolution [22]. While individual nerve cells in tissue of the nervous system can be identified using phase contrast, osmium tetroxide staining can be used to label the myelin sheath around the axon, allowing identification of several sub-cellular structures [23]. As with CT staining more generally, staining of specific cell structures for hard $\mathrm{nCT}$ is in its infancy, and establishing a library of stains to label different organelles would be of great benefit.

$\mu \mathrm{CT}$ is proving particularly useful for the imaging of biomaterial tissue scaffolds intended to replace and regenerate tissues and organs of the body. These materials are not generally optically transparent or easily sectioned, making their 3D analysis challenging by light and electron microscopy. Scaffolds may be ceramic, metallic, polymeric or hydrogel, and extracellular matrix (ECM) produced by the cells may be made of calcified or soft tissues. $\mu \mathrm{CT}$ imaging is well suited to analysing the formation of mineralised tissue on polymeric and ceramic scaffolds as mineralised tissue has a high X-ray absorption and so can be easily distinguished using conventional X-ray attenuation imaging [77] (Fig. 5b). Quantitative 3D data can be obtained, including scaffold porosity, interconnectivity, volume and surface area, along with calcified tissue volume, distribution and density [18]. $\mu \mathrm{CT}$ imaging of soft tissue production on a polymeric scaffold or hydrogel poses a greater challenge compared with mineralised tissues since polymers and soft tissue attenuate X-rays similarly, resulting in poor X-ray contrast. This has been addressed by the use of either heavy metal contrast agents [78] or PCT imaging (Fig. 5a) [22]. Quantitative analysis has been undertaken of the depth and distribution of cellular infiltration into the scaffold [78]. Imaging of non-mineralised ECM production on metallic biomaterials presents different challenges. While high energy X-rays are typically used to image metals, the low X-ray attenuation associated with soft tissues at high energies mean that they cannot easily be discerned. For these applications, protocols have been developed to increase the X-ray opacity of the developing non-mineralised ECM, allowing visualisation of the ECM formation using high-energy X-rays [79].

\section{Correlative imaging}

Correlative light and electron microscopy exploits light microscopy to image fluorescent markers and identify particular molecules as well as proteins (e.g. [80]), whilst electron microscopy provides the ultrastructural context. Similarly, correlative CT exploits multiple techniques or imaging modalities to obtain different types of information from a given ROI or volume of interest [81]. Data can also be correlated across images acquired at different times (temporal correlation), for example to observe mineral formation over time in 3D scaffolds [18], or across multiple length scales using multi-scale CT, sometimes termed zoom tomography, as used to identify the location of macrophages within mouse lung [16].

Conventional histological analysis has been combined with $\mu \mathrm{CT}$ as a means of both validating $\mathrm{CT}$ and also to verify the different tissue types within a given sample
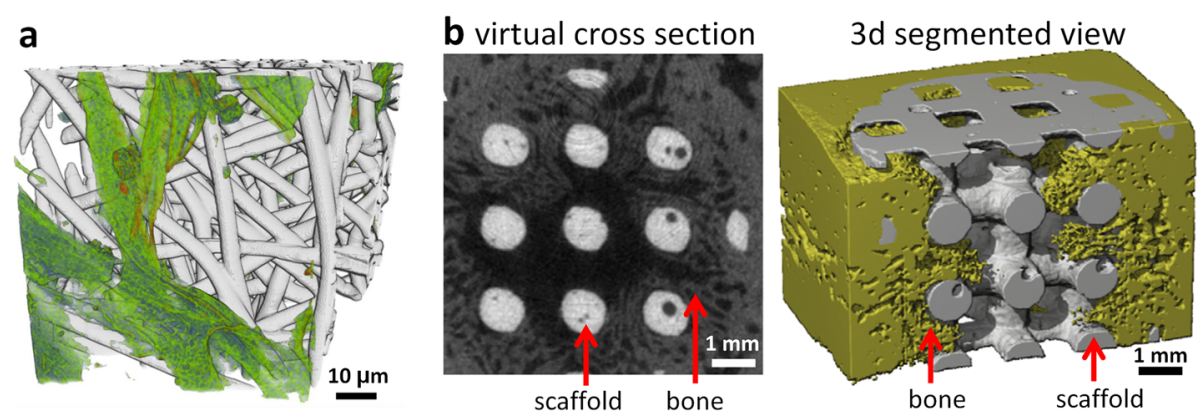

Fig. 5 Imaging of cells and tissues on biomaterial scaffolds. a Segmented 3D nCT reconstruction of human fibroblast cells (green) on a poly (lactide-co-glycolide) (PLGA) fibre scaffold (grey), reproduced with permission from [22]. b Virtual cross-section (left) alongside a 3D segmented $\mu \mathrm{CT}$ reconstruction (right) showing bone in-growth on a hydroxyapatite scaffold after 6 weeks implantation within a critical size defect of a Yucatan minipig mandible [77] Image in b reprinted from [77], Biomaterials, 28(15), van Lenthe GH, Hagenmuller H, Bohner M, Hollister SJ, Meinel L, Muller R. Nondestructive micro-computed tomography for biological imaging and quantification of scaffold-bone interaction in vivo, p.2479-90, 2007, with permission from Elsevier 
[82]. During the correlative study of cartilage, PCT-enhanced $\mu \mathrm{CT}$ surpassed histological analysis: comparable spatial resolution was achieved across both techniques but $\mu C T$ provided 3D data [83]. Another application for correlative $\mu \mathrm{CT}$ with light microscopy is to assess both cell viability and 3D cellular infiltration in biomaterial applications. Soluble assays are used to determine cell viability, followed by $\mu \mathrm{CT}$, which provides complementary data on cell infiltration and distribution within the scaffold in 3D, often unattainable by other means, thus allowing a richer understanding of the samples [84]. Similarly, 3D nCT has been used for the imaging of cells alongside optical microscopy of fluorescent labels to identify organelles within the cell [85].

$\mu \mathrm{CT}$ has also been proposed as a means of experimental steering ahead of more detailed and time-consuming serial block face SEM [56]. Serial block face SEM involves the automated sequence of material removal (via ultramicrotome or focussed ion beam milling) of a stained and embedded sample followed by SEM imaging of the cut surface of the block to construct a 3D volume from the imaged slices, e.g. of tendons [86]. 3D volumes of $50-\mu \mathrm{m}$ dimensions are commonly imaged by serial section focussed ion beam milling and SEM, while volumes of $500 \mu \mathrm{m}$ are common by ultramicrotomy and SEM. CT experimental steering can be used to enable high-throughput pre-screening of multiple samples, to identify samples containing specific rare features, to ensure adequate sample preparation prior to serial block face SEM studies, to steer 3D serial sectioning workflows, to locate specific features for detailed site-specific investigation, to provide an overview of the sample from which higher-resolution electron microscopy images are acquired or to assess the extent of sample preparation artefacts [56].

To ensure appropriate registry when undertaking multiscale correlative imaging, fiducial markers (e.g. gold or tungsten carbide particles) are often used when transferring samples between instruments to locate the same ROI and to align the resulting data sets. A fiducial marker can take any form, either an intentional notch or scratch in the sample or an embedded small item or particle, which can be identified from the CT scan. For example, Zehbe et al. [83] used a screw as a marker to ensure imaging of the exact same cell with both tomography and subsequent light microscopy of stained histological sections. Similarly, Walton et al. [34] used gold beads $(1-3 \mu \mathrm{m}$ diameter) as fiducial markers to locate the same region within the rat aorta wall (Fig. 6).

Whilst in its infancy, correlative lightsheet fluorescent microscopy (LSFM) and CT imaging can enable the imaging of small and large features, respectively [87]. During LSFM imaging, the sample is illuminated with a laser, which is focused to a sheet of light only a few microns in thickness, and the detection axis is perpendicular to illumination. In-focus light is imaged simultaneously rather than pixel by pixel as in conventional confocal microscopy, and the narrow plane of focus of the laser also reduces phototoxicity and photobleaching [88]. Lightsheet has been applied to studying nervous system development in the transparent zebrafish, which has been correlated with visible light tomography to provide anatomical context (Fig. 7a, b) [89]. A limited number of studies have sought to compare LSFM with $\mu \mathrm{CT}$, observing the murine cochlea [90] or carotid artery and micro-vascular networks [87]. Buytaert et al. [90] correlated LSFM data to $\mu \mathrm{CT}$ in the study of the mouse cochlea and obtained high-resolution images of anatomical, morphological and histological organisation of soft tissue from LSFM, the results of which were comparable to those obtainable from histological analysis (Fig. 7c, d). The $\mu C T$ data were used correlatively alongside LSFM to provide more accurate dimensional information, which is especially important to combat the effects of shrinkage from LSFM sample staining [90]. A limitation of LSFM is the requirement for optically transparent samples. Opaque tissue samples must be cleared to increase optical penetration depth, but the clearing process can lead to a significant amount of tissue shrinkage [91]. As an alternative to clearing, advances in equipment are now available that can pivot the lightsheet to provide improved imaging for more opaque samples [92].

Given that the form and function of biological tissue is determined from the molecular up to the whole-organism scale, multi-scale CT can be particularly useful. The whole sample can be mapped at the highest magnification, but it is more often experimentally and data efficient to follow a targeted trajectory tracking specific ROIs [93]. In some cases it is possible to traverse the scales non-invasively using ROI scanning [13] to investigate ROIs at increasing magnifications. In other cases it is necessary to remove a ROI for investigation by CT or electron microscopy at successively higher resolutions. Xenon plasma focussed ion beam milling has proven an effective technique for excising suitable regions of interest [3] as it provides accurate material removal at a rapid rate when compared with conventional gallium focussed ion beam milling. One challenging aspect of correlative imaging is identifying the same area of interest for subsequent scans when transferring a sample between equipment (when moving from $\mu \mathrm{CT}$ to $\mathrm{nCT}$ for example). Fiducial markers are typically used for this purpose (e.g. surface markings [94] and metallic particles). Walton et al. applied multiscale CT imaging to the study of rat arterial walls using micro- and then nano-PCT of unstained, wax-embedded samples [34] (Fig. 6). From the $\mathrm{nCT}$ (150 nm spatial resolution), individual medial lamellae could be identified and segmented, whilst $\mu \mathrm{CT}$ provided wider context to their arrangement within the whole artery 

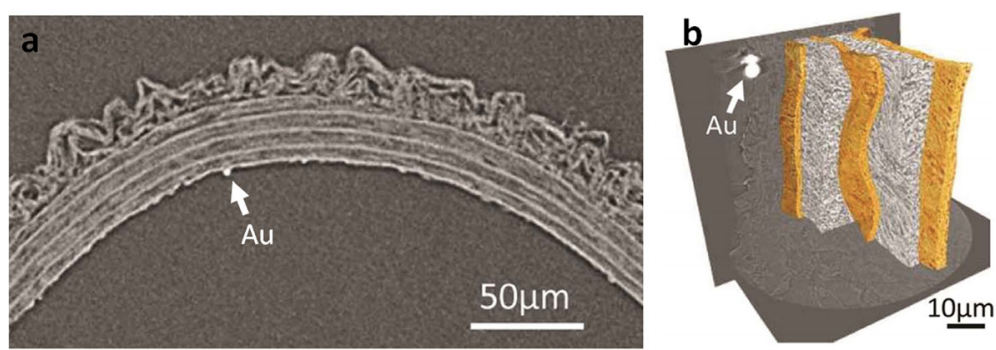

Fig. 6 Gold fiducial marker (Au) in a rat aorta, allowing co-registry of multi-scale CT imaging, reproduced with permission from [34]. a Virtual cross-section through $\mu \mathrm{CT}$ data at a spatial resolution of $0.7 \mu \mathrm{m}$. b Segmented reconstruction of $\mathrm{nCT}$ data at $150 \mathrm{~nm}$ spatial resolution


Fig. 7 LSFM with complementary $\mu \mathrm{CT}$ and visible light tomography. a, b Zebrafish (lateral view) imaged using correlative LSF and visible light tomography, showing a head of the zebrafish and $\mathbf{b}$ larger view to show detail. Red = vasculature, green = nervous system [89]. $\mathbf{c}$, $\mathbf{d}$ Cross-section through the segmented reconstruction of the midmodiolar section of the mouse right ear, imaged using $\mathbf{c} L S F M$ and $\mathbf{d} \mu C T$. From the LSFM data, 15 tissue types can be identified: bone (white), spiral ligament (turquoise), saccule (pale purple), stria vascularis (dark purple), tectorial membrane (green), scala media (cream), basilar membrane (yellow with white arrowhead), Rosenthal's canal (orange), Claudius cells (pale pink), modiolus (bright pink), organ of Corti (bright red), scala tympani (dark red), scala vestibuli (pale blue), spiral limbus (mid-blue), osseous spiral lamina (dark blue). From the $\mu \mathrm{CT}$ data, four tissue types can be identified: bone (white), cochlea scalae and vestibular labyrinth (blue), Rosenthal's canal (orange) and modiolus (pink) [90] Images in a and b reproduced with permission from [89], Development: Bassi A, Schmid B, Huisken J, Development, 2015, 142(5):1016-20. Images in c and d reproduced with permission from [90] 
[34]. Similar multiscale work has been performed in the study of human tooth dentine $[16,94]$.

When considering biominerals, studies have used backscattered electron imaging and electron backscatter diffraction to determine areas of different mineral phases and grain crystallographic orientation, respectively, as exemplified in the study of aragonite and calcite crystal forms of calcium carbonate in Anoteropora latirostris (saltwater invertebrates which live in interconnected colonies) [95]. Correlating electron microscopy with subsequent $\mu \mathrm{CT}$ is particularly useful in providing wider context for the crystallographic data, demonstrating how it relates to the wider architecture of the A. latirostris colony, allowing inference towards biomineral deposition during colonial development (which begins at the colony centre) (Fig. 8) [95]. Further to this, X-ray diffraction can inform on grain structure and orientation in 3D. Correlative X-ray diffraction and $\mu \mathrm{CT}$ has been applied to fossilised bone samples to determine hydroxyapatite orientation and infer muscle attachment sites, previously only achievable destructively using polarised light microscopy after sample sectioning [96]. Multi-modal data correlation is challenging, particularly when spanning several orders of magnitude and when involving 3D data sets; however, developments in software are approaching automated correlation, making data management more practical [93]. Correlation software has been used in the study of the acorn barnacle Semibalanus balanoides, using light microscopy, $\mu \mathrm{CT}$, scanning electron microscopy, scanning electron microscopy and electron backscatter diffraction correlatively, spanning several orders of magnitude [97].

\section{Tracking microstructural changes within a sample over time}

Since CT is non-invasive, sequences of images can be acquired to observe changes over time, termed timelapse $\mu \mathrm{CT}$. For example, temporal studies are improving our understanding of biomaterial degradation in a fluidflow environment [98], water transport in plants [35] and plant root growth [99]. These techniques have also been applied to tissues that require mechanical stress for homeostasis, such as musculoskeletal tissues [25], or respond to internal pressure, such as arteries [34]. Mechanical loading studies are also of interest for investigating damage to tissues [100], or the damage tolerance of an implanted device [26], for instance.

Live cell imaging over time is of particular relevance for the tracking of therapeutic cells in vivo and for the analysis of tissue-engineered (TE) scaffolds. For biomaterials research, longitudinal time-lapse studies are possible where either conventional X-ray attenuation imaging or PCT imaging provides sufficient contrast such that no toxic stains are necessary and the dose is not sufficient to affect the viability of the cells. In the case of high attenuating calcified tissue on polymer or ceramic scaffolds, X-ray attenuation imaging has been used to identify scaffold degradation and tissue volume, infiltration and density over time during in vitro culture
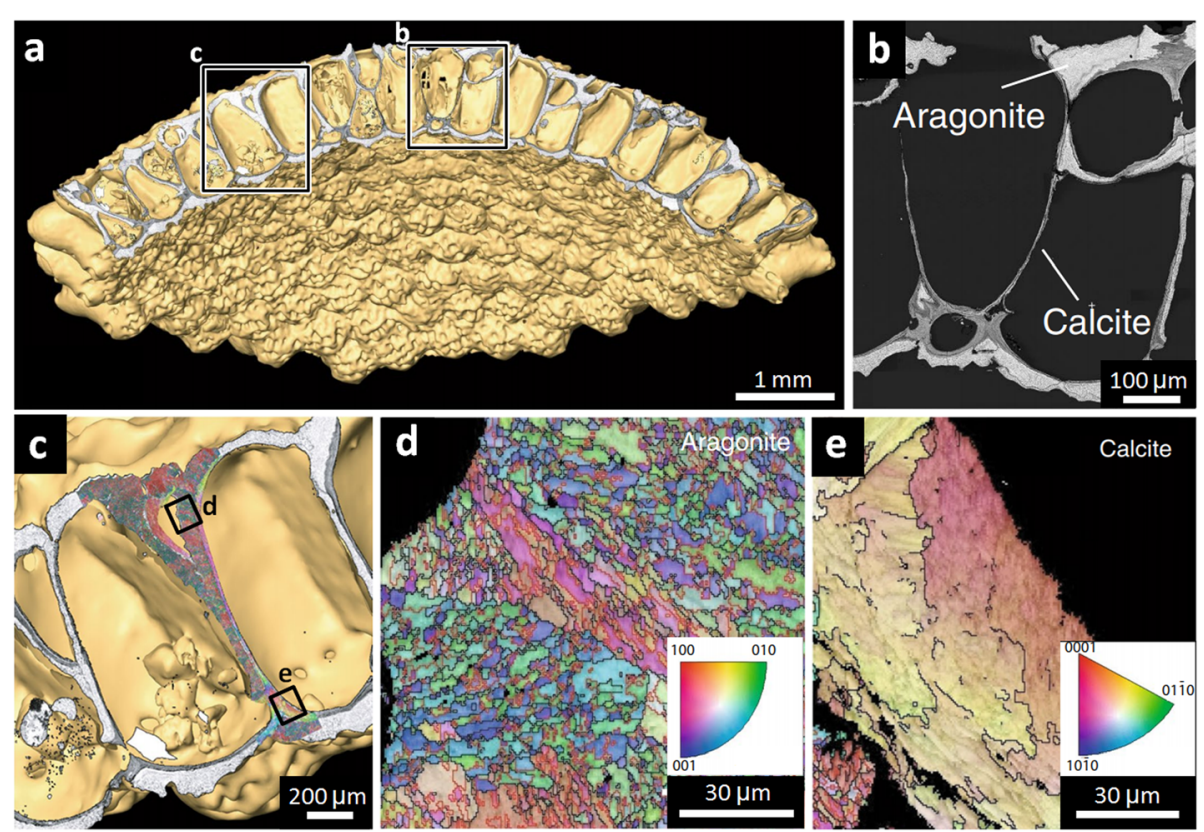

Fig. 8 Correlative microscopy of the anoteropora latirostris (saltwater invertebrate) colony, reproduced with permission from [95]. a CT of the colony. $\mathbf{b}$ Backscattered electron imaging showing aragonite and calcite regions. $\mathbf{c}$ Electron backscatter diffraction overlaid onto CT volume data. d, e High-resolution electron backscatter diffraction data, showing crystallographic grain structure in the $\mathbf{d}$ aragonite and e calcite regions 
[18]. For soft tissues on polymeric and hydrogel scaffolds, which exhibits poor contrast during X-ray attenuation imaging, PCT has allowed quantitative analysis of biomaterial degradation and integration into host tissue over time in a subcutaneous murine in vivo study [101]. Due to repeated $\mathrm{X}$-ray exposure, retaining cell function is of concern for time lapse $\mu \mathrm{CT}$ imaging of cellularised scaffolds both in vitro and in vivo. One study observing mineralised matrix formation by rat stromal and calavarial cells reported no reduction in mineralised matrix formation resulting from weekly $\mu \mathrm{CT}$ scans at $16 \mu \mathrm{m}$ isotropic voxel size [18]. Conversely, at higher spatial resolutions $(50 \mathrm{~nm})$, studies have found structural damage to samples [16], which can be minimised by freezing; however, this introduces added concerns over freezethaw damage in potential longitudinal studies. There is currently no recommended X-ray limit for longitudinal studies; inroads have been made towards identifying Xray settings that impose minimal dosages whilst producing adequate scans for TE and in vivo applications, specifically for a cartilage TE implant in a porcine knee joint [102]. Further in vivo studies for wider TE products would be beneficial, as would establishing guidelines on the maximum $\mathrm{X}$-ray dosage that does not alter in vitro cellular function.

Time-lapse $\mu$ CT has also proven useful in the study of developing root systems, resulting in greater understanding of the root-soil interface in different soil types, and unexpectedly demonstrating reduced root-soil contact and increased soil porosity over time [103]. As with longitudinal studies of live cells, X-ray exposure is a concern. For live plants, a recommended cumulative dose limit of $33 \mathrm{~Gy}$ has been proposed [104]; however, some plant species are particularly sensitive to X-rays. The date and plum exhibit impaired germination at $0.05 \mathrm{Gg}$ [104] and the fava bean shows reduced root and leaf growth in longitudinal studies reaching a cumulative dose of 8 Gy (Fig. 9) [99]. Caution is therefore advised, and unexposed controls are recommended.

\section{CT imaging considerations}

Several practical aspects with regards to CT imaging must be considered, including acquisition time, cost, equipment access, image processing and data management.

In general, as spatial resolution is increased the required scan time also increases (see the "Obtaining contrast for soft tissue imaging in aqueous conditions" section). Whereas laboratory-based X-ray $\mu \mathrm{CT}$ may take a few hours, $\mathrm{nCT}$ can be expected to require at least double this amount of time [105]. However, acquisition time limitations can largely be overcome by exploiting the high brightness of synchrotron X-ray sources. Depending on the required resolution, as many as ten scans per second can be acquired [12]. High frame rate CT

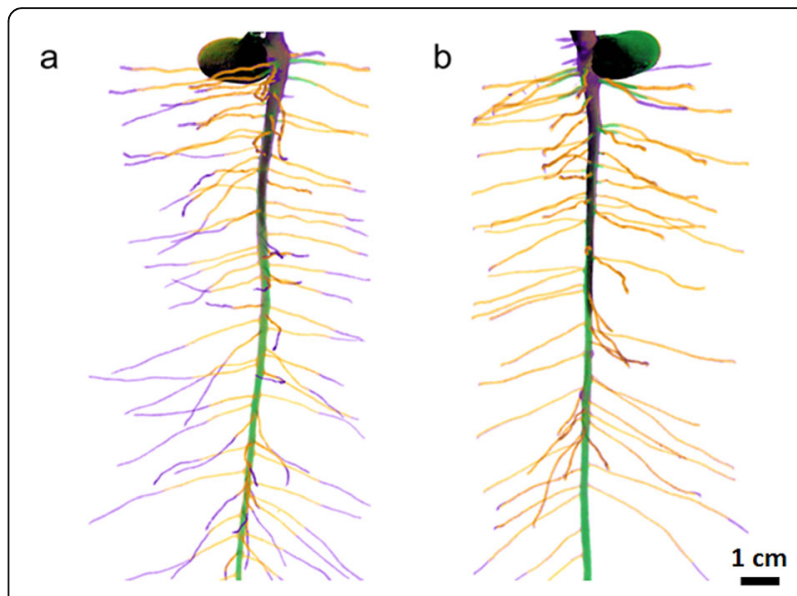

Fig. 9 Time-lapse imaging of a fava bean root showing impaired growth with increased imaging rate, reproduced with permission from [99]. a Imaged every 2 days. b Imaged every 4 days. Colour represents number of days after planting: black $=4$, green $=8$, orange $=12$ and purple $=16$

imaging generates very large amounts of data very quickly, which can be challenging to manage, and which takes considerable time and effort to analyse. Given that there are relatively few large scale synchrotron facilities globally, access is limited and often restricted to a few days at a time, prohibiting certain longitudinal studies.

Segmentation of $3 \mathrm{D} \mu \mathrm{CT}$ and $\mathrm{nCT}$ data sets can be time-consuming, especially if manual intervention is required to delineate different regions or phases within each slice in turn. In cases where time-lapse data are acquired, quantification is necessarily reliant on automated segmentation and quantification procedures because of the sheer volume of data to be analysed in 4D. Looking forwards, segmentation of CT datasets is set to benefit from the emergence of machine learning techniques, which are currently in development within the medical field for disease recognition and to approach personalised medicine [106] as well as in other fields of computer vision analysis [93].

\section{Conclusions and future perspectives}

The capability of laboratory and synchrotron CT imaging is increasing apace in terms of acquisition rate, spatial resolution and sensitivity [12]. At present, laboratory source $\mathrm{nCT}$ and high resolution $\mu \mathrm{CT}$ can take hours or days to acquire a scan while those at tens of microns can take seconds or minutes. The brilliance of synchrotron sources mean acquisition rates can be some 1000 times faster, meaning that at present fast acquisition is best undertaken at synchrotrons, whereas longer or dose-sensitive samples may be better suited for laboratory $\mu \mathrm{CT}$. Increases in acquisition rates at laboratory sources would be particularly beneficial for imaging of fresh, un-fixed specimens, and to allow practical imaging 
of replicates of samples and during longitudinal studies where multiple scans are necessary. This can be achieved by reducing the number of projections taken through the $360^{\circ}$ rotation of the sample, or by reducing the projection time, which in turn reduces X-ray counts. Iterative reconstruction algorithms are now available to allow reliable reconstruction of tomography data obtained in shorter times, with no significant detriment to imaging quality [107].

The efforts to improve speed, spatial resolution and sensitivity may also provide the possibility of imaging at the same resolution as currently available, but at lower Xray dose. This is of specific concern for biological specimens during longitudinal studies where repeated exposure is necessary and of increasing relevance at greater spatial resolution. Whilst reducing X-ray exposure would undoubtedly be beneficial, the literature on the effects of Xrays (of different energies) on cells during $\mu \mathrm{CT}$ and $\mathrm{nCT}$ imaging is sparse with no specific guidance on exposure limits for research. Establishing the X-ray dosage levels that cause either a decline in function or cell death, across a variety of cell lines, would be beneficial fundamental research to provide confidence in longitudinal studies where cells are repeatedly imaged.

Correlative imaging, either between multiple machines or within single instruments, is becoming more popular. The key challenge for correlative tomography is the ability to co-register and combine data from multiple modalities. Software is currently available that enables alignment of predominantly 2D data sets for correlative light and electron microscopy, and has some 3D capability to correlate between focussed ion beam SEM, CT and light microscopy; however, software allowing improved automated correlation of 3D data sets is under development [108].

Improving the efficiency and automation of the segmentation stage of data analysis would be particularly beneficial from a practical perspective, allowing a greater number of sample replicates to be analysed in a practical amount of time. Automated segmentation processes are currently available, but these are not effective when there is high noise or poor contrast in the data. Efforts to improve imaging quality (improved sensitivity, improved contrast and reduced noise) may enable automated segmentation with greater ease. In addition, development is ongoing into improving the automated segmentation capabilities of software through methods such as machine learning [109]. The application of CT to the life sciences is increasing, complementing traditional light and electron microscopy, and is likely to increase further with further advances in capability and analysis procedures.

\section{Acknowledgments}

We are grateful for the funding from the European Research Council (ERC) for supporting this research, which provided funding under the European
Commission's Horizon 2020 (FP8/2014-2020) ERC grant agreement number 695638 (CORREL-CT). Further, we would also like to acknowledge the Engineering and Physical Sciences Research Council (EPSRC) and the Medical Research Council for funding towards this research (EP/L014904/1). This work was supported by the Henry Royce Institute for Advanced Materials, funded through EPSRC grants EP/R00661X/1, EP/P025021/1 and EP/P025498/1.

Authors' contributions

All authors have read and approved the final version.

Funding

As above.

Availability of data and materials

Not applicable.

\section{Competing interests}

The authors declare that they have no competing interests.

Published online: 27 February 2020

\section{References}

1. Smith D, Starborg T. Serial block face scanning electron microscopy in cell biology: applications and technology. Tissue Cell. 2018;57:111-22.

2. Shearer T, Bradley RS, Hidalgo-Bastida LA, Sherratt MJ, Cartmell SH. Threedimensional visualisation of soft biological structures by $\mathrm{X}$-ray computed micro-tomography. J Cell Sci. 2016;129(13):2483-92.

3. Burnett $T L$, Kelley R, Winiarski B, Contreras L, Daly M, Gholinia A, et al. Large volume serial section tomography by Xe plasma FIB dual beam microscopy. Ultramicroscopy. 2016;161:119-29.

4. McDermott G, Le Gros MA, Knoechel CG, Uchida M, Larabell CA. Soft X-ray tomography and cryogenic light microscopy: the cool combination in cellular imaging. Trends Cell Biol. 2009;19(11):587-95.

5. Truong TV, Supatto W, Koos DS, Choi JM, Fraser SE. Deep and fast live imaging with two-photon scanned light-sheet microscopy. Nat Methods. 2011;8(9):757-60.

6. Elliott JC, Dover SD. X-ray microtomography. J Microsc. 1982;126:211-3 https://doi.org/10.1111/j.1365-2818.1982.tb00376.x.

7. Marxen JC, Prymark O, Beckmann F, Neues F, Epple M. Embryonic shell formation in the snail Biomphalaria glabrata: a comparison between scanning electron microscopy (SEM) and synchrotron radiation micro computer tomography (SRHCT). J Molluscan Stud. 2008;74(1):19-26.

8. Bradley RS, Withers PJ. Post-processing techniques for making reliable measurements from curve-skeletons. Comput Biol Med. 2016;72:120-31.

9. Prakasam M, Chirazi A, Pyka G, Prokhodtseva A, Lichau D, Largeteau A. Fabrication and multiscale structural properties of interconnected porous biomaterial for tissue engineering by freeze isostatic pressure (FIP). J Funct Biomater. 2018;9(3):51.

10. Topperwien M, van der Meer F, Stadelmann C, Salditt T. Three-dimensional virtual histology of human cerebellum by $\mathrm{X}$-ray phase-contrast tomography. Proc Natl Acad Sci U S A. 2018;115(27):6940-5.

11. Genant HK, Block JE, Steiger P, Glueer CC, Smith R. Quantitative computed tomography in assessment of osteoporosis. Semin Nucl Med. 1987;17(4): 316-33.

12. Maire E, Withers PJ. Quantitative X-ray tomography. Int Mater Rev. 2014; 59(1):1-43.

13. Kyrieleis A, Titarenko V, Ibison M, Connolley T, Withers PJ. Region-of-interest tomography using filtered backprojection: assessing the practical limits. J Microsc. 2011;241(1):69-82.

14. O'Sullivan JDB, Behnsen J, Starborg T, MacDonald AS, Phythian-Adams AT, Else $\mathrm{K}$, et al. X-ray micro-computed tomography $(\mu \mathrm{CT})$ : an emerging opportunity in parasite imaging. Parasitology. 2018;145(7):848-54.

15. Withers PJ. X-ray nanotomography. Mater Today. 2007;10(12):26-34.

16. Krenkel M, Markus A, Bartels M, Dullin C, Alves F, Salditt T. Phase-contrast zoom tomography reveals precise locations of macrophages in mouse lungs. Sci Rep UK. 2015:5:9973.

17. Pena Fernandez M, Cipiccia S, Dall'Ara E, Bodey AJ, Parwani R, Pani M, et al. Effect of SR-microCT radiation on the mechanical integrity of trabecular bone using in situ mechanical testing and digital volume correlation. J Mech Behav Biomed Mater. 2018;88:109-19. 
18. Cartmell S, Huynh K, Lin A, Nagaraja S, Guldberg R. Quantitative microcomputed tomography analysis of mineralization within threedimensional scaffolds in vitro. J Biomed Mater Res A. 2004;69(1):97-104.

19. Duke E, Dent K, Razi M, Collinson LM. Biological applications of cryo-soft Xray tomography. J Microsc Oxford. 2014;255(2):65-70.

20. Immel A, Le Cabec A, Bonazzi M, Herbig A, Temming H, Schuenemann VJ, et al. Effect of X-ray irradiation on ancient DNA in sub-fossil bones guidelines for safe X-ray imaging. Sci Rep. 2016;6:32969.

21. Diaz A, Malkova B, Holler M, Guizar-Sicairos M, Lima E, Panneels V, et al. Three-dimensional mass density mapping of cellular ultrastructure by ptychographic X-ray nanotomography. J Struct Biol. 2015;192(3):461-9.

22. Bradley RS, Robinson IK, Yusuf M. 3D X-ray nanotomography of cells grown on electrospun scaffolds. Macromol Biosci. 2017;17(2):1600236. https://doi. org/10.1002/mabi.201600236.

23. Bartels M, Krenkel M, Cloetens P, Mobius W, Salditt T. Myelinated mouse nerves studied by X-ray phase contrast zoom tomography. J Struct Biol. 2015;192(3):561-8.

24. Meir R, Shamalov K, Betzer O, Motiei M, Horovitz-Fried M, Yehuda R, et al. Nanomedicine for cancer immunotherapy: tracking cancer-specific T-cells in vivo with gold nanoparticles and CT imaging. ACS Nano. 2015;9(6):6363-72.

25. Schulte FA, Ruffoni D, Lambers FM, Christen D, Webster DJ, Kuhn G, et al. Local mechanical stimuli regulate bone formation and resorption in mice at the tissue level. PLoS One. 2013;8(4):e62172.

26. Rawson SD, Shearer T, Lowe T, O'Brien M, Wong JKF, Margetts L, et al. Fourdimensional imaging of soft tissue and implanted biomaterial mechanics: a barbed suture case study for tendon repair. ACS Appl Mater Interfaces. 2018;10(45):38681-91.

27. Bech M, Tapfer A, Velroyen A, Yaroshenko A, Pauwels B, Hostens J, et al. Invivo dark-field and phase-contrast x-ray imaging. Sci Rep UK. 2013;3:3209. https://doi.org/10.1038/srep03209.

28. Gignac PM, Kley NJ. lodine-enhanced micro-CT imaging: methodological refinements for the study of the soft-tissue anatomy of post-embryonic vertebrates. J Exp Zool B Mol Dev Evol. 2014;322(3):166-76. https://doi.org/ 10.1002/jez.b.22561.

29. Disney CM, Eckersley A, McConnell JC, Geng H, Bodey AJ, Hoyland JA, et al. Synchrotron tomography of intervertebral disc deformation quantified by digital volume correlation reveals microstructural influence on strain patterns. Acta Biomater. 2019;92:290-304.

30. Endrizzi M. X-ray phase-contrast imaging. Nuclear Inst Methods Physics Res A. 2018;878:88-98.

31. Taiwo OO, Finegan DP, Gelb J, Holzner C, Brett DJL, Shearing PR. The use of contrast enhancement techniques in $\mathrm{X}$-ray imaging of lithium-ion battery electrodes. Chem Eng Sci. 2016;154:27-33.

32. Ismail EC, Kaabar W, Garrity D, Gundogdu O, Bunk O, Pfeiffer F, et al. X-ray phase contrast imaging of the bone-cartilage interface. Appl Radiat Isot. 2010;68(4-5):767-71.

33. Schulz G, Gotz C, Muller-Gerbl M, Zanette I, Zdora MC, Khimchenko A, et al. Multimodal imaging of the human knee down to the cellular level. J Phys Conf Ser. 2017;849(1):012026.

34. Walton LA, Bradley RS, Withers PJ, Newton VL, Watson RE, Austin C, et al. Morphological characterisation of unstained and intact tissue microarchitecture by X-ray computed micro- and nano-tomography. Sci Rep. 2015;5:10074. https://doi.org/10.1038/srep10074.

35. Karunakaran C, Lahlali R, Zhu N, Webb AM, Schmidt M, Fransishyn K, et al. Factors influencing real time internal structural visualization and dynamic process monitoring in plants using synchrotron-based phase contrast X-ray imaging. Sci Rep. 2015;5:12119.

36. McNeil A, Bradley RS, Withers PJ, Penney D. Imaging fossilised spiders in amber using lab-based phase contrast X-ray tomography. Proc SPIE. 2010 https://doi.org/10.1117/12.873024.

37. Metscher BD. MicroCT for comparative morphology: simple staining methods allow high-contrast 3D imaging of diverse non-mineralized animal tissues. BMC Physiol. 2009;9:11.

38. Gignac PM, Kley NJ, Clarke JA, Colbert MW, Morhardt AC, Cerio D, et al. Diffusible iodine-based contrast-enhanced computed tomography (diceCT): an emerging tool for rapid, high-resolution, 3-D imaging of metazoan soft tissues. J Anat. 2016;228(6):889-909.

39. Staedler YM, Kreisberger T, Manafzadeh S, Chartier M, Handschuh S, Pamperl $\mathrm{S}$, et al. Novel computed tomography-based tools reliably quantify plant reproductive investment. J Exp Bot. 2018;69(3):525-35.
40. Faulwetter S, Dailianis T, Vasileiadou A, Arvanitidis C. Contrast enhancing techniques for the application of micro-CT in marine biodiversity studies. Microsc Anal. 2013;2(27):S2-7.

41. Gamisch A, Staedler YM, Schonenberger J, Fischer GA, Comes HP. Histological and micro-CT evidence of stigmatic rostellum receptivity promoting auto-pollination in the madagascan orchid Bulbophyllum bicoloratum. PLoS One. 2013;8(8):e72688.

42. Scheller EL, Troiano N, Vanhoutan JN, Bouxsein MA, Fretz JA, Xi Y, et al. Use of osmium tetroxide staining with microcomputerized tomography to visualize and quantify bone marrow adipose tissue in vivo. Methods Enzymol. 2014;537:123-39.

43. Metscher BD. MicroCT for developmental biology: a versatile tool for highcontrast 3D imaging at histological resolutions. Dev Dyn. 2009;238(3):632-40.

44. Dunmore-Buyze PJ, Cruje C, Nong Z, Lee JJ, Kiernan JA, Pickering JG, et al. $3 \mathrm{D}$ vessel-wall virtual histology of whole-body perfused mice using a novel heavy element stain. Sci Rep. 2019;9(1):698.

45. Pauwels E, Van Loo D, Cornillie P, Brabant L, Van Hoorebeke L. An exploratory study of contrast agents for soft tissue visualization by means of high resolution X-ray computed tomography imaging. J Microsc. 2013; 250(1):21-31.

46. Koc MM, Aslan N, Kao AP, Barber AH. Evaluation of X-ray tomography contrast agents: a review of production, protocols, and biological applications. Microsc Res Tech. 2019. https://doi.org/10.1002/jemt.23225.

47. Li Z, Ketcham RA, Yan F, Maisano JA, Clarke JA. Comparison and evaluation of the effectiveness of two approaches of diffusible iodine-based contrastenhanced computed tomography (diceCT) for avian cephalic material. J Exp Zool B Mol Dev Evol. 2016;326(6):352-62.

48. de Souza Martins ESJ, Utsch J, Kimm MA, Allner S, Epple MF, Achterhold K et al. Dual-energy micro-CT for quantifying the time-course and staining characteristics of ex-vivo animal organs treated with iodine- and gadolinium-based contrast agents. Sci Rep. 2017;7(1):17387.

49. Li Z-H, Yan F, Ketcham RA, Colbert MW, Clarke JA. Mass-transfer based modeling to investigate iodine staining effects for enhanced contrast $X$-ray computed tomography. Paleoworld. 2018; https://doi.org/10.1016/j.palwor. 2018.10.004

50. Butters TD, Castro SJ, Lowe T, Zhang Y, Lei M, Withers PJ, et al. Optimal iodine staining of cardiac tissue for X-ray computed tomography. PLoS One. 2014;9(8):e105552.

51. Meyer EP, Ulmann-Schuler A, Staufenbiel M, Krucker T. Altered morphology and $3 \mathrm{D}$ architecture of brain vasculature in a mouse model for Alzheimer's disease. Proc Natl Acad Sci U S A. 2008;105(9):3587-92.

52. Vickerton $P$, Jarvis J, Jeffery N. Concentration-dependent specimen shrinkage in iodine-enhanced microCT. J Anat. 2013;223(2):185-93.

53. Lee JT, Chow KL. SEM sample preparation for cells on 3D scaffolds by freeze-drying and HMDS. Scanning. 2012;34(1):12-25.

54. Wehrl HF, Bezrukov I, Wiehr S, Lehnhoff M, Fuchs K, Mannheim JG, et al. Assessment of murine brain tissue shrinkage caused by different histological fixatives using magnetic resonance and computed tomography imaging. Histol Histopathol. 2015;30(5):601-13.

55. Verleden $S E$, Vasilescu DM, Willems $S$, Ruttens $D$, Vos R, Vandermeulen E, et al. The site and nature of airway obstruction after lung transplantation. Am J Respir Crit Care Med. 2014;189(3):292-300.

56. Starborg T, O'Sullivan JDB, Carneiro CM, Behnsen J, Else KJ, Grencis RK, et al. Experimental steering of electron microscopy studies using prior $\mathrm{X}$-ray computed tomography. Ultramicroscopy. 2019;201:58-67.

57. Vasilescu DM, Phillion AB, Tanabe N, Kinose D, Paige DF, Kantrowitz JJ, et al. Nondestructive cryomicro-CT imaging enables structural and molecular analysis of human lung tissue. J Appl Physiol (1985). 2017;122(1):161-9.

58. Disney CM, Madi K, Bodey AJ, Lee PD, Hoyland JA, Sherratt MJ. Visualising the $3 \mathrm{D}$ microstructure of stained and native intervertebral discs using X-ray microtomography. Sci Rep. 2017;7(1):16279.

59. Astolfo A, Qie F, Kibleur A, Hao X, Menk RH, Arfelli F, et al. A simple way to track single gold-loaded alginate microcapsules using $x$-ray $C T$ in small animal longitudinal studies. Nanomedicine. 2014;10(8):1821-8.

60. Uchida M, Sun Y, McDermott G, Knoechel C, Le Gros MA, Parkinson D, et al. Quantitative analysis of yeast internal architecture using soft X-ray tomography. Yeast. 2011;28(3):227-36. https://doi.org/10.1002/yea.1834.

61. Elgass KD, Smith EA, LeGros MA, Larabell CA, Ryan MT. Analysis of ERmitochondria contacts using correlative fluorescence microscopy and soft X-ray tomography of mammalian cells. J Cell Sci. 2015;128(15):2795-804. https://doi.org/10.1242/jcs.169136. 
62. Handschuh S, Beisser CJ, Ruthensteiner B, Metscher BD. Microscopic dualenergy $C T$ (microDECT): a flexible tool for multichannel ex vivo 3D imaging of biological specimens. J Microsc. 2017;267(1):3-26. https://doi.org/10.1111/ jmi.12543.

63. Murphy CJ, Gole AM, Stone JW, Sisco PN, Alkilany AM, Goldsmith EC, et al. Gold nanoparticles in biology: beyond toxicity to cellular imaging. Acc Chem Res. 2008;41(12):1721-30

64. Fan J, Li W, Hung W, Chen C, Yeh J. Cytotoxicity and differentiation effects of gold nanoparticles to human bone marrow mesenchymal stem cells. Biomed Eng Appl Basis Commun. 2011;23:141-52.

65. Betzer O, Meir R, Dreifuss T, Shamalov K, Motiei M, Shwartz A, et al. In-vitro optimization of nanoparticle-cell labeling protocols for in-vivo cell tracking applications. Sci Rep. 2015;5:15400.

66. Mok PL, Leow SN, Koh AE, Mohd Nizam HH, Ding SL, Luu C, et al. Micro-computed tomography detection of gold nanoparticle-labelled mesenchymal stem cells in the rat subretinal layer. Int J Mol Sci. 2017; 18(2):345.

67. Chhour P, Naha PC, O'Neill SM, Litt HI, Reilly MP, Ferrari VA, et al. Labeling monocytes with gold nanoparticles to track their recruitment in atherosclerosis with computed tomography. Biomaterials. 2016;87:93-103.

68. Oliveira-Filho EC, Filho JS, Novais LA, Peternele WS, Azevedo RB, Grisolia CK. Effects of gamma-Fe2O3 nanoparticles on the survival and reproduction of Biomphalaria glabrata (say, 1818) and their elimination from this benthic aquatic snail. Environ Sci Pollut Res Int. 2016;23(18):18362-8.

69. Yamamoto $Y$, Shinohara K. Application of X-ray microscopy in analysis of living hydrated cells. Anat Rec. 2002;269(5):217-23.

70. Carlson DB, Gelb J, Palshin V, Evans JE. Laboratory-based cryogenic soft Xray tomography with correlative cryo-light and electron microscopy. Microsc Microanal. 2013;19(1):22-9.

71. Johnson TRC. Dual-energy CT: general principles. Am J Roentgenol. 2012;199(5):S3-8.

72. Panta RK, Bell ST, Healy JL, Aamir R, Bateman CJ, Moghiseh M, et al. Element-specific spectral imaging of multiple contrast agents: a phantom study. J Instrum. 2018;13:T02001.

73. Egan CK, Jacques SD, Wilson MD, Veale MC, Seller P, Beale AM, et al. 3D chemical imaging in the laboratory by hyperspectral X-ray computed tomography. Sci Rep. 2015;5:15979.

74. Stampanoni M, Mokso R, Marone F, Vila-Comamala J, Gorelick S, Trtik P, et al. Phase-contrast tomography at the nanoscale using hard $x$ rays. Phys Rev B. 2010;81(14). https://doi.org/10.1103/PhysRevB.81.140105.

75. Harkiolaki M, Darrow MC, Spink MC, Kosior E, Dent K, Duke E. Cryo-soft X-ray tomography: using soft X-rays to explore the ultrastructure of whole cells. Emerging Topics Life Sci. 2018;2:81-92.

76. Langer M, Pacureanu A, Suhonen H, Grimal Q, Cloetens P, Peyrin F. X-ray phase nanotomography resolves the 3D human bone ultrastructure. PLoS One. 2012;7(8):e35691.

77. van Lenthe GH, Hagenmuller H, Bohner M, Hollister SJ, Meinel L, Muller R. Nondestructive micro-computed tomography for biological imaging and quantification of scaffold-bone interaction in vivo. Biomaterials. 2007;28(15): 2479-90.

78. Dorsey SM, Lin-Gibson S, Simon CG Jr. X-ray microcomputed tomography for the measurement of cell adhesionand proliferation in polymer scaffolds. Biomaterials. 2009;30(16):2967-74.

79. Stradiotti P, Curti A, Castellazzi G, Zerbi A. Metal-related artifacts in instrumented spine. Techniques for reducing artifacts in CT and MRI: state of the art. Eur Spine J. 2009;18(Suppl 1):102-8.

80. Shu X, Lev-Ram V, Deerinck TJ, Qi Y, Ramko EB, Davidson MW, et al. A genetically encoded tag for correlated light and electron microscopy of intact cells, tissues, and organisms. PLoS Biol. 2011;9:e1001041.

81. Bradley RS, Withers PJ. Correlative multiscale tomography of biological materials. Adv Tomogr Tech Mater Appl. 2016:41(7):549-56.

82. Nunez JA, Goring A, Hesse E, Thurner PJ, Schneider P, Clarkin CE. Simultaneous visualisation of calcified bone microstructure and intracortical vasculature using synchrotron X-ray phase contrast-enhanced tomography. Sci Rep. 2017;7(1):13289.

83. Zehbe R, Riesemeier H, Kirkpatrick CJ, Brochhausen C. Imaging of articular cartilage-data matching using X-ray tomography, SEM, FIB slicing and conventional histology. Micron. 2012;43(10):1060-7.

84. Brunelli M, Perrault CM, Lacroix D. Short bursts of cyclic mechanical compression modulate tissue formation in a 3D hybrid scaffold. J Mech Behav Biomed Mater. 2017;71:165-74.
85. Schneider G, Guttmann P, Rehbein S, Werner S, Follath R. Cryo X-ray microscope with flat sample geometry for correlative fluorescence and nanoscale tomographic imaging. J Struct Biol. 2012;177(2):212-23.

86. Kalson NS, Lu Y, Taylor SH, Starborg T, Holmes DF, Kadler KE. A structurebased extracellular matrix expansion mechanism of fibrous tissue growth. Elife. 2015;4. https://doi.org/10.7554/eLife.05958.

87. Epah J, Palfi K, Dienst FL, Malacarne PF, Bremer R, Salamon M, et al. 3D imaging and quantitative analysis of vascular networks: a comparison of ultramicroscopy and micro-computed tomography. Theranostics. 2018;8(8): 2117-33.

88. Power RM, Huisken J. A guide to light-sheet fluorescence microscopy for multiscale imaging. Nat Methods. 2017;14(4):360-73.

89. Bassi A, Schmid B, Huisken J. Optical tomography complements light sheet microscopy for in toto imaging of zebrafish development. Development. 2015;142(5):1016-20. https://doi.org/10.1242/dev.116970.

90. Buytaert JA, Johnson SB, Dierick M, Salih WH, Santi PA. MicroCT versus sTSLIM 3D imaging of the mouse cochlea. J Histochem Cytochem. 2013; 61(5):382-95. https://doi.org/10.1369/0022155413478613.

91. Buytaert J, Goyens J, De Greef D, Aerts P, Dirckx J. Volume shrinkage of bone, brain and muscle tissue in sample preparation for micro-CT and light sheet fluorescence microscopy (LSFM). Microsc Microanal. 2014;20(4):1208-17.

92. Zeiss. Lightsheet Z.1. https://www.zeiss.com/microscopy/int/light/lightsheetz-1.html. Accessed 11 Dec 2018.

93. Burnett TL, Withers PJ. Completing the picture through correlative characterization. Nat Mater. 2019;18(10):1041-9.

94. Burnett TL, Winiarski B, Kelley R, Zhong XL, Boona IN, McComb DW, et al. $\mathrm{Xe}+$ plasma FIB: 3D microstructures from nanometers to hundreds of micrometers. Microsc Today. 2016;24(3):32-9.

95. Jacob DE, Ruthensteiner B, Trimby P, Henry H, Martha SO, Leitner J, et al. Architecture of Anoteropora latirostris (Bryozoa, Cheilostomata) and implications for their biomineralization. Sci Rep Uk. 2019;9:1143 https://doi. org/10.1038/s41598-019-47848-4.

96. Murer FK, Sanchez S, Alvarez-Murga M, Di Michiel M, Pfeiffer F, Bech M, et al 3D maps of mineral composition and hydroxyapatite orientation in fossil bone samples obtained by X-ray diffraction computed tomography. Sci Rep. 2018;8(1):10052

97. Mitchell RL, Coleman M, Davies P, North L, Pope EC, Pleydell-Pearce C, et al. Macro-to-nanoscale investigation of wall-plate joints in the acorn barnacle Semibalanus balanoides: correlative imaging, biological form and function, and bioinspiration. J R Soc Interface. 2019;16(157):20190218.

98. Zeller-Plumhoff B, Helmholz H, Feyerabend F, Dose T, Wilde F, Hipp A, et al. Quantitative characterization of degradation processes in situ by means of a bioreactor coupled flow chamber under physiological conditions using time-lapse SRHCT. Mater Corros. 2018;69(3):298-306.

99. Blaser S, Schluter S, Vetterlein D. How much is too much?-influence of X-ray dose on root growth of faba bean (Vicia faba) and barley (Hordeum vulgare). PLoS One. 2018;13(3):e0193669. https://doi.org/10.1371/journal. pone.0193669.

100. Mustansar Z, McDonald SA, Sellers WI, Manning PL, Lowe T, Withers PJ, et al. A study of the progression of damage in an axially loaded Branta leucopsis femur using X-ray computed tomography and digital image correlation. PeerJ. 2017:5:e3416.

101. Olubamiji AD, Zhu N, Chang T, Nwankwo CK, Izadifar Z, Honaramooz A, et al. Traditional invasive and synchrotron-based noninvasive assessments of three-dimensional-printed hybrid cartilage constructs in situ. Tissue Eng Part C Methods. 2017;23(3):156-68.

102. Izadifar Z, Honaramooz A, Wiebe S, Belev G, Chen X, Chapman D. Data of low-dose phase-based $X$-ray imaging for in situ soft tissue engineering assessments. Data Brief. 2016;6:644-51.

103. Helliwell JR, Sturrock CJ, Mairhofer S, Craigon J, Ashton RW, Miller AJ, et al. The emergent rhizosphere: imaging the development of the porous architecture at the root-soil interface. Sci Rep UK. 2017;7(1):14875.

104. Zappala S, Helliwell JR, Tracy SR, Mairhofer S, Sturrock CJ, Pridmore T, et al. Effects of $X$-ray dose on rhizosphere studies using X-ray computed tomography. PLoS One. 2013;8(6):e67250.

105. Hoffmann R, Schultz JA, Schellhorn R, Rybacki E, Keupp H, Lemanis $R$, et al. Non-invasive imaging methods applied to neo-and paleo-ontological cephalopod research. Biogeosciences. 2014;11:2721-39.

106. Xie Q, Faust K, Van Ommeren R, Sheikh A, Djuric U, Diamandis P. Deep learning for image analysis: personalizing medicine closer to the point of care. Crit Rev Clin Lab Sci. 2019;56(1):61-73. 
107. Qinyang L, Andrew M, Thompson M, Blunt MJ, Bijeljic B. Optimization of image quality and acquisition time for lab-based X-ray microtomography using an iterative reconstruction algorithm. Adv Water Resour. 2018;115: $112-24$.

108. Harkiolaki M. Correlative soft-X Ray cryo-tomography and super resolution fluorescence microscopy imaging for the life sciences at diamond light source beamline B24. Conference proceedings, ToScA. UK: University of Warwick; 2018

109. Anwar SM, Majid M, Qayyum A, Awais M, Alnowami M, Khan MK. Medical image analysis using convolutional neural networks: a review. J Med Syst. 2018;42(11):226

\section{Publisher's Note}

Springer Nature remains neutral with regard to jurisdictional claims in published maps and institutional affiliations. 